\title{
Producción y circulación del saber en la historia del campo bibliotecario argentino
}

Javier Planas

Instituto de Investigaciones en Humanidades y Ciencias Sociales (UNLP-CONICET), Argentina I jplanas@fahce.unlp.edu.ar / http://orcid.org/oooo-0001-5989-1467

\begin{abstract}
Resumen
El ensayo tiene como objetivo establecer una serie de problemas elementales para el estudio de las relaciones entre la formación y el desarrollo del campo bibliotecario argentino y sus maneras consagradas de producción y circulación del saber entre 1870 y 1999. En términos teóricos y metodológicos, se construye una articulación entre los conceptos "campo" (que permite una indagación sincrónica) e "institución" (que brinda una perspectiva diacrónica) para estudiar un conjunto de documentos vinculados con la historia de las bibliotecas y de la Bibliotecología en Argentina. Como resultado, se presenta una periodización tentativa que consta de tres momentos: emergencia (1870-1910); prolongación y expansión (1910-1960); especialización (1960-1999). Cada etapa se diferencia de la otra por la definición de sus problemáticas: 1) hacer la biblioteca en lo social; 2) expandir el espacio y el saber que le son socialmente necesarios; 3) profesionalizar el campo. A modo de conclusión, se evalúa el aporte original del artículo, en relación con la efectividad de los conceptos utilizados y a las constataciones historiográficas encontradas. Entre otros aspectos, se destaca la potencialidad heurística del archivo que testimonia el saber bibliotecario.
\end{abstract}

\section{Production and circulation of knowledge in the history of the Argentine library field}

\footnotetext{
Abstract

The object of this work is to establish a series of elementary problems for the study of the relationships between the formation and development of the Argentinean library field and its consecrated ways of production and circulation of knowledge between 1870 and 1999. In theoretical and methodological terms, an articulation between the concepts "field" (which allows a synchronic inquiry) and "institution" (which provides a diachronic perspective) is constructed to study a set of documents related to the

\section{Palabras clave}

Campo bibliotecario Historia Social del Conocimiento Bibliotecología argentina Saber bibliotecario.
Field librarian Social history of knowledge Librarianship argentina Librarian knowledge 
history of libraries and librarianship in Argentina. As a result, a tentative periodization consisting of three moments is presented: Emergence (1870-1910); prolongation and expansion (1910-1960); specialization (1960-1999). Each stage differs from the other by defining its problems: 1 ) To develop the social aspect of the library; 2) To expand the space and knowledge that are socially necessary; 3) To professionalize the library field. By way of conclusion, the original contribution of the article is evaluated, in relation to the effectiveness of the concepts used and the historiographic findings found. Among other aspects, the heuristic potential of the archive that testifies the librarian knowledge stands out.

Artículo recibido: 21-12-2018. Aceptado: 24-04-2019

\section{Introducción}

El presente trabajo busca establecer una periodización que contenga una serie de problemas elementales para el estudio de las relaciones entre la formación y el desarrollo del campo bibliotecario argentino y sus maneras consagradas de producción y circulación del saber a lo largo de la historia. Los antecedentes bibliográficos que contribuyen con la construcción de este singular objeto de conocimiento son escasos. Se cuenta, sin embargo, con algunas investigaciones que de forma separada buscaron asir esos dos ámbitos. De un lado, la historia de la institucionalización social de las bibliotecas y de la disciplina en Argentina fue revisada en dos momentos clave: en los albores de la profesionalización de los bibliotecarios por Federico Finó y Luis Hourcade (1952); después, por Alejandro Parada (2009) en un momento de franca consolidación de la Bibliotecología en Argentina - en términos institucionales y cognitivos-. El primero de estos dos estudios procuró establecer una tradición sobre la cual fundar la inserción de la enseñanza de la materia en las instituciones pedagógicas que, si bien se había iniciado dos décadas atrás, sus bases y fundamentos eran incipientes. El carácter descriptivo de la investigación no menoscaba el valor de sus resultados, que establecen una primera periodización para comprender las transformaciones históricas de las bibliotecas y de la Bibliotecología en el país. Esta calidad se ratifica en el análisis que para el mismo objeto hizo Parada medio siglo después. En líneas generales, este autor puso en consideración algunos textos fundacionales publicados en el siglo XIX, renovó la lectura historiográfica sobre las transformaciones de las bibliotecas y, también, completó con información los procesos bibliotecarios que siguieron a la publicación del artículo de Finó y Hourcade al iniciarse la década de 1950.

Por otro lado, la indagación sobre las maneras de circulación del saber en el campo bibliotecológico cuenta con un trabajo señero como el que realizó Susana Romanos de Tiratel y equipo (2008). Se trata, en rigor, de un estudio panorámico sobre la visibilidad de las revistas de humanidades y ciencias sociales argentinas en las bases de datos internacionales hasta 2004, acompañado por un apartado histórico y contextual sobre el desarrollo de las publicaciones periódicas de cada disciplina (Filología, Literatura y Lingüística, Filosofía, Historia, Antropología, Economía, Bibliotecología). Esta última sección representa una continuidad del enfoque metodológico que lleva implícita la delimitación del concepto "revista científica" como representación de las lógicas comunicativas de lo científico y, con ello, la identificación o asimilación del conocimiento legítimo de los campos con esas reglas. Este criterio, que resulta pertinente para el objeto propuesto por la autora, es inviable para pensar el campo bibliotecario y las maneras en que este produjo su conocimiento legítimo y lo hizo circular - desde su objetivación como tal- a partir de la segunda mitad del siglo XIX. En primer lugar, habría que reconsiderar el estatuto ontológico de la noción de "revista científica", tal como lo hizo Rafael Capurro en "¿Qué es una revista científica?" (2015). Allí queda 
demostrado que el concepto no representó siempre y unívocamente el mismo orden de cosas y que, por lo tanto, reconocer el pasado de las periódicas de una disciplina -en este caso de la Bibliotecología- demanda olvidarse de las definiciones contemporáneas y pensar, en cambio, en los modos de producción del saber socialmente dado en cada época y sus dinámicas respectivas de circulación. Un testimonio tangible de esta afirmación requiere considerar un segundo antecedente; se trata de la Bibliografía Bibliotecológica Argentina [hasta 1967], compilada por Nicolás Matijevic (1969) y prologada por Josefa Emilia Sabor. La obra reúne más de 2.500 asientos bibliográficos que representan a su tiempo una pluralidad de temas, modalidades de publicación y tipologías documentales de las que se valieron los bibliotecarios (graduados o de oficio) para modelar su propio campo, desde el siglo XIX hasta el final de la década de 1960. Si bien el carácter enumerativo del trabajo impide apreciar las calidades de los estudios compilados - como señala la propia Sabor-, la suma de todos ellos confirma una disposición bibliotecológica, es decir: una voluntad del saber que entraña la estructuración de un espacio de conocimiento distintivo con aspiraciones técnicas y científicas. Aun cuando muchos de estos resultados hayan dejado muy poco o nada en términos de rigurosidad o eficacia, sus autores tuvieron una aspiración legítima sobre la definición del objeto de estudio y la competencia bibliotecaria.

\section{Aspectos conceptuales y metodológicos}

El hecho de que los textos citados de manera precedente como puntos de partida no formen parte de un mismo debate obliga a recalibrar algunos de sus postulados y a relegar otros para favorecer la construcción de un objeto de estudio que, al partir de las constataciones evaluadas - y de las fuentes documentales que se suman en el desarrollo del presente artículo-, enlace los procesos que hacen a la radicación social de las bibliotecas y de la Bibliotecología con aquellos que se vinculan a las formas de elaboración y circulación del saber que le son propias. En este contexto, la noción de campo propuesta por Pierre Bourdieu (2002) permite definir un primer movimiento metodológico para ordenar esas dimensiones, que solo están disociadas en términos analíticos, pero que en rigor contienen una misma forma de experiencia. Un campo es, entonces, una delimitación teórica que permite asir de manera sincrónica un ámbito estructurado de carácter específico (campo científico, intelectual, político, artístico, etc.), cuyo objeto de interés o capital en disputa hace que los concurrentes se especialicen progresivamente en los saberes y las prácticas del campo (disposición), con la intención de alcanzar las posiciones más ventajosas dentro de dicha estructura. Aun cuando los que se disputan esos lugares están en desacuerdo y luchan por imponer su autoridad sobre los demás, debajo de los antagonistas se extiende un acuerdo implícito que los reúne (doxa) y que impide, por lo mismo, la disolución del campo.

Poner a punto esa noción en los límites que supone la producción bibliotecaria de la Argentina -en términos cognitivos y sociales-, requiere recapitular, clasificar, ordenar y comprender un corpus documental compuesto, a la vez, de dos series diferenciales de fuentes a menudo yuxtapuestas: de un lado, el archivo que contiene la historia de las bibliotecas; de otro, el que se forma como consecuencia del devenir de esa historia y se expande en organizaciones y discursos progresivamente especializados. Las relaciones entre un ámbito y otro - representadas aquí por los vestigios que dejaron a su paso- no son otra que los procesos de emergencia y prolongación de la institución de la biblioteca, en el sentido que la tradición filosófica francesa del siglo XX le dio al término institución, es decir, no como organización singular o conjunto de tales, sino como la sucesión de acontecimientos de potencia durable que funda una experiencia social sobre la cual se asientan otras que le son venideras y que solo en ella adquieren sentido (Merleau-Ponty, 2012). 
Si la noción institución tiene alcances de largo aliento -o se advierte con claridad en la dimensión diacrónica del objeto-, el concepto campo permite aislar unas aprehensiones sincrónicas que, enlazadas, nos devuelven al proceso de institución mencionado. En este trabajo se recorren tres instancias o estados del campo mutuamente vinculados. El primero (1870-1910), refiere a la emergencia del campo bibliotecario en Argentina y a las incipientes formas de producción del saber que acontecieron como consecuencia; el segundo (1910-1960), registra los procesos zigzagueantes de profesionalización, caracterizados por una voluntad de saber que busca la especialidad sin encontrar la diferenciación adecuada y sin alcanzar, aún, un estatuto satisfactorio dentro del juego más amplio de relaciones de posición que propone el campo científico, que es el ámbito al que los bibliotecarios aspiraron integrar; finalmente, el tercer corte (1960-1999) propone examinar la consolidación del campo bibliotecario, al focalizar la atención en las estructuras universitarias y en las reglas del juego que los actores involucrados en estas instancias de producción del saber hacen valer sobre el resto de concurrentes.

\section{La emergencia del campo bibliotecario: saberes legítimos y publicaciones (1870-1910)}

Existe una interrogación inmanente a todo el proceso bibliotecario de entresiglos; una pregunta que funciona como la doxa que reúne a los fundadores del campo, que es propiamente como podemos identificar a sus concurrentes durante este período. La cuestión, sin embargo, no se ubica en una obra, en una institución, en las incipientes técnicas de ordenación, en las zigzagueantes políticas de Estado o en las voluntades que el azar reunió junto a la idea todavía inestable de biblioteca. Tampoco es verificable en la yuxtaposición de estas variantes que, por lo demás, actúan como sus efectos. Se trata de una pregunta que es, esencialmente, un emergente. Su lógica atañe a la producción social de la lectura, a la combinación de los artificios según los cuales existe la necesidad de la lectura, en sus diferentes inscripciones y niveles de jerarquización. Todo lo que es percibido como biblioteca durante el momento instituyente se define en términos procedimentales. Esto significa que aquellos que participaron de la emergencia de este campo, con las perspectivas y las intervenciones antagónicas que esto supone, lo hicieron sobre el acuerdo tácito de "hacer la biblioteca en lo social".

Este hacer la biblioteca en lo social supuso la acumulación de recursos medibles en tiempo y en objetivaciones institucionales necesarias para vivificar en el imaginario la representación de una biblioteca, esto es: la idea sencilla pero poderosa de la reunión de libros y de la creación elemental de una nueva rutina institucional dentro del conjunto de rutinas que rigen la sociedad. De aquí que el campo bibliotecario, así como también los sucesivos estados verificables en el tiempo -incluido la formación de la Bibliotecología como disciplina practicada-, son el producto singular de la historia de las bibliotecas.

No puede desconocerse, dentro de la tradición decimonónica, el hecho fundamental y perdurable que, en sus consecuencias materiales inmediatas y en sus resonancias simbólicas de largo alcance, significó la fundación de la Biblioteca Pública de Buenos Aires en el contexto de la Revolución de Mayo (Parada, 2009, 2014; González, 2010). Por primera vez, en una escala cualitativa desconocida hasta entonces - considerando que el acceso público a las bibliotecas de tradición colonial era verdaderamente escaso-, se puso a disposición de un conjunto de lectores un amplio repertorio de libros que, hasta hacía poco tiempo, estaban en manos privadas. Este fenómeno asoció en un mismo movimiento y de manera novedosa la vinculación entre la biblioteca y el Estado, por una parte, y la biblioteca con la sociedad civil, por otra. 
El resultado de esa asociación no generó, desde ya, nada parecido a lo que hoy reconocemos como una política de Estado. Por lo demás, el contexto de la guerra de independencia que siguió a 1810 detuvo todos los esfuerzos materiales de legitimación social y simbólicamente concebidos que el primer gobierno patrio, en la figura de Mariano Moreno, había diseñado en términos de dispositivo de instrucción. La limitación territorial y el escaso público lector que hizo uso de esas colecciones y de esas instalaciones no produjeron una fuerza de convencimiento social en relación a la biblioteca como necesidad, como institución. Aun así, la Biblioteca Pública de Buenos Aires logró permanecer como una representación entre las generaciones de letrados que confluyeron en lo sucesivo en las disputas políticas por la construcción del Estado nacional.

Paradójicamente, el segundo hito de la historia de las bibliotecas en Argentina se construyó en oposición a la Biblioteca Pública de Buenos Aires. Se trata de la expansión de las bibliotecas populares en el inicio década de 1870 a partir de la sanción de la Ley 419 (Planas, 2017). En un contexto político completamente diferente, la normativa adoptada por aquel entonces generaba un modelo de gestación sustentado en las intervenciones de la sociedad civil. Como estímulo, el Estado brindaba una subvención igual al dinero recolectado por cada asociación y ofrecía tramitar la inversión de ambas contribuciones en libros, así como también hacer el envío del material sin costo adicional. La autonomía administrativa de las bibliotecas y la libre elección de las obras constituyeron una clave fundamental, no solo porque estas cualidades representaron un atractivo para las asociaciones, sino también porque el gobierno aligeró con ello las cargas presupuestarias en el área de instrucción pública mediante la delegación de funciones en las sociedades. La simplicidad del sistema, las gestiones de la Comisión Protectora de las Bibliotecas Populares y la buena recepción que tuvo la política alentaron un movimiento bibliotecario que superó las expectativas de los funcionarios: entre 1870 y 1875 las bibliotecas formaban parte del paisaje de un centenar de pueblos y ciudades de todo el territorio nacional. A partir de entonces amplios sectores de la sociedad tuvieron una manifestación material de la idea de biblioteca, pero de una manera radicalmente distinta a la forma en que había funcionado la Biblioteca Pública de Buenos Aires. Solo para referirnos a la transformación bibliotecológica, cabría consignar que las bibliotecas populares hicieron posible el préstamo domiciliario de libros, probablemente la innovación más radical en relación con la tradición imperante. El concepto de biblioteca no solo se modificó, sino que definitivamente pasó a integrar el imaginario social, es decir: el conjunto de valores, representaciones, sentimientos, sueños y deseos que las personas mantienen, consensuan y disputan acerca de cómo debe componerse una sociedad (Baczko, 1999).

En el polo opuesto, entonces, a esta cristalización institucional y social que significó la biblioteca popular, la Biblioteca Pública de Buenos Aires entró en un proceso de redefinición que la asoció a la producción de la cultura científica y, por lo mismo, la alejó progresivamente de la noción de "pública" que manejamos en la actualidad. Resulta imprescindible observar que tras la conversión de la ciudad de Buenos Aires en Capital Federal y, en consecuencia, con la nacionalización de la Biblioteca, la provincia de Buenos Aires buscó instituir en la ciudad de La Plata una nueva y poderosa metrópoli, a cuyos efectos destinó tiempo y recursos a la formación de una biblioteca que se hizo a semejanza de la institución perdida. Esto es: un establecimiento cuyas colecciones, horarios y público se encaminaron hacia la atención del conjunto de necesidades progresivamente crecientes generadas por la investigación científica. De manera que, si ya existía entre los letrados de antaño una creencia en el concepto de biblioteca como realización social, ahora bajo el nuevo esquema de comprensión de la realidad que generó el positivismo finisecular, la biblioteca resignificó su estatuto y funcionalidad, incorporándose ahora como un engranaje en la reproducción de la cultura científica. 
Las bibliotecas populares, desde sus propios planos de actuación, contribuyeron a la reproducción del esquema de interpretación social provisto por el positivismo. De manera que también vieron desplazado su sentido genético, aunque no lo abandonaron, esto es: se alejaron de su posición como instituciones puestas a democratizar el uso de los libros para constituirse como lugares de formación pedagógica de la sociedad. En el final del siglo XIX, las denominadas bibliotecas obreras disputaron el público que le estaba conferido a las populares, pero siempre sobre la base de un acuerdo sólido: los lectores populares requerían de un acompañamiento inicial en el sinuoso mundo de la lectura (Planas, 2018).

Entonces, entre el último tercio del siglo XIX y la primera década del siglo XX tuvieron lugar las objetivaciones bibliotecarias fundamentales para la emergencia del campo. En este marco, también tuvo lugar, aunque de manera dispersa, la construcción del saber socialmente requerido para la organización de las bibliotecas. Y es esta construcción la que generó lo que podemos reconocer como efectos de campo, es decir: que ningún hecho u obra puede comprenderse de manera independiente a la producción de otros hechos y otras obras elaboradas sobre una doxa que ya es, entonces, una inmanencia.

El Boletín de las Bibliotecas Populares (1872-1875) es, con toda seguridad, un testimonio tangible del momento de radicación social de las bibliotecas. Con tan solo 6 números, esta fue la primera publicación periódica de Bibliotecología del país. Su misión era facilitar una didáctica para la creación y el funcionamiento de las bibliotecas. Los procedimientos utilizados en su confección no fueron los que ordinariamente se emplean en la comunicación de la ciencia; tampoco el contenido de sus artículos promovió una reflexión teórica de la disciplina ni propició la circulación de resultados de investigación. No obstante, su producción cumplió con el nivel básico pero significativamente relevante desde el punto de vista sociocultural requerido para responder a la pregunta por el cómo de una biblioteca.

En la misma época las revistas de educación comenzaron a dedicarle algunas de sus páginas a la circulación de las ideas bibliotecarias. La disputa entre Domingo Faustino Sarmiento $(1877 \mathrm{a}, 1877 \mathrm{~b})$ y Vicente Quesada $(1877,1879)$ a propósito del destino de la Biblioteca Pública de Buenos Aires en 1877 explica, por la disidencia misma, la fijación de un objeto (Planas, 2017). Retrospectivamente no importa si Quesada justificaba o no con la publicación de Bibliotecas Europeas y algunas de América Latina (1877) el montaje de una institución que miraba hacia la cultura científica (Buchbinder, 2018). Tampoco interesa si Sarmiento acertaba con la idea de refundar el establecimiento y hacerlo público en el sentido norteamericano. Lo que resulta significativo es el movimiento cognoscitivo que propició, ponderable en la voluntad de establecer unos horizontes conceptuales.

Esta voluntad por brindarle inteligibilidad a un objeto se expandió, como quedó dicho, de manera progresiva y en relación con la producción objetiva de la biblioteca en lo social. Lo procedimental adquirió preponderancia en los textos sobre bibliotecas: entre las décadas de 1880 y 1910 proliferan las publicaciones que procuran brindar alguna respuesta a preguntas como: ¿de qué manera armar un catálogo? ¿Cómo ordenar los libros en el estante? ¿Qué sistemas de clasificación utilizar? ¿Cómo formar una colección? Luis Ricardo Fors (1900) desde la Biblioteca Pública de la Provincia de Buenos Aires con sede en La Plata publicó, por ejemplo, unas instrucciones para ingresar los apellidos de los autores en el catálogo. Federico Birabén (1904), desde la Universidad de Buenos Aires (cuya revista, dicho sea de paso, sirvió para canalizar durante largos años algunos de los trabajos del campo), introdujo el flamante sistema de Clasificación Decimal Universal. Y en una perspectiva totalmente diferente, Paul Groussac confeccionó y publicó en 1893 en el Catálogo Metódico de la Biblioteca. En el 
diario socialista La Vanguardia aparecieron varios artículos relacionados con el hacer de las bibliotecas (Sik, 2016; Tripaldi, 1997). Los anarquistas desde La Protesta también hicieron lo propio (Sik, 2018). Sin embargo, una obra singular parece destacarse entre todas las mencionadas como testimonio del efecto de campo que ya existía en 1910: se trata de la monografía que escribió Amador Lucero (1910) por encargo del Ministerio de Educación: Nuestras bibliotecas desde 1810. En ese entonces, para decir algo sobre el estado de las bibliotecas en el contexto del primer Centenario del gobierno patrio, el autor requirió referirse a la tradición bibliotecaria en la argentina. Esto es: ninguna biblioteca $\mathrm{u}$ obra referida a las bibliotecas era independiente de un pasado hecho tradición, ni de un campo convertido en presente.

\section{Prolongación y expansión del campo: temas y ámbitos de circulación (1910-1960)}

Entre el Centenario y el final de la década de 1950 el campo bibliotecario argentino consolidó una lógica de producción del conocimiento progresivamente sistemática, orgánica y especializada, de manera paralela a la multiplicación de los establecimientos bibliotecarios y a la fijación de la imagen de la biblioteca en la sociedad. En el extremo inicial del período, sus preocupaciones principales fueron construidas sobre dos ejes semánticos cuya articulación epistemológica estuvo asociada a los horizontes del positivismo nacional: por un lado, los avatares de la documentación y los proyectos bibliográficos, en sus encarnaciones conceptuales y metodológicas de corte universalista, latinoamericanista o panamericanista (Menéndez Navarro et al, 2002); por otro, la institución de un pensamiento sobre la biblioteca afincado entre la organización de los impresos, en especial, jalonado por las técnicas catalográficas y la constitución de un discurso público de la lectura de carácter moralizante, higienista y nacionalista (Planas, 2018). Hacia el final de esta etapa las empresas bibliográficas trasnacionales perdieron la gravitación que tuvieron como motores disciplinares, mientras que los procesos bibliotecarios y la formación del ciudadano mediante dispositivos jerarquizados de lectura se mantuvieron intactos como instancias creativas. Se sumaron, no obstante, otras preocupaciones: la formación de los bibliotecarios y la comprensión y el tratamiento de los nuevos soportes de la información (grabaciones sonoras, microfilms, audiovisuales, etc.). Si el primer aspecto había sido esbozado tímidamente en el pasado, el segundo constituyó, a posteriori, los cimientos de un sentido ontológico de la Bibliotecología contemporánea: la tecnología (Laudano et al, 2011).

Una de las razones fundamentales que postergaron la aparición de las revistas académicas o científicas durante este largo período estuvo asociada a la jerarquía que los autores de entonces le atribuyeron al artículo como tipo documental. Carlos Victor Penna, una de las figuras centrales de la bibliotecología argentina y latinoamericana, se refería de este modo a la bibliografía de la disciplina:

De la producción que podríamos llamar menor, y que se encuentra representada por ensayos, estudios y experiencias publicadas en artículos aparecidos en revistas, debemos admitir que sería posible reseñar un importante número de contribuciones, algunas de las cuales, si fuesen desarrolladas in-extenso, podrían dar lugar a obras de importancia. Muchas revistas han dado cabida a artículos bibliotecológicos y en tal sentido, aparte de las publicaciones de las bibliotecas nacionales u organismos de parecida categoría, ciertas publicaciones universitarias han ofrecido sus páginas a nuestros profesionales (Penna, 1960).

El libro fue la forma y la unidad de sentido sustantiva del conocimiento bibliotecológico hasta la mitad del siglo XX. No obstante, muchos de los trabajos monográficos que circularon en la época salieron con antelación bajo la forma de ensayos 
breves en revistas de diferente índole y anclaje institucional, esto es: desde el Boletín (1933-1947) de la Comisión Protectora de las Bibliotecas Populares, relanzado por Juan Pablo Echagüe en 1933 para brindar sustento cognoscitivo a estas instituciones, hasta Universidad (1935-1965), la publicación de la Universidad Nacional del Litoral. Esta última concentró en sus primeros 50 números publicados entre 1935 y 1961 más de 70 artículos de orden bibliotecológico, documental y bibliográfico. Es decir: una frecuencia nada desdeñable que superó ligeramente un trabajo por número. Domingo Buonocore o Alfredo Cónsole, entre otros autores que pudieran citarse, encontraron en este órgano una vía para la difusión de textos preliminares que más adelante acabaron compilados, reelaborados y editados en un volumen coherente. No es que los bibliotecarios desdeñaron las publicaciones periódicas como espacios para el intercambio de ideas, sino que las veían como contextos propicios para dar a conocer avances de proyectos de mayor envergadura y, por consiguiente, de mayor sustancia disciplinar. Por lo demás, su práctica laboral en los ámbitos académicos los situó en una posición estratégica para comprender la relevancia de este medio de comunicación y los dilemas implicados con su procesamiento. Marta Montes de Oca, la bibliotecaria que organizó el índice analítico de Universidad, lo precisó con estas palabras: "En las bibliotecas modernas las publicaciones periódicas constituyen el elemento primordial para la actualización de información, pero su incesante crecimiento hace imprescindible la existencia de índices que agilicen su consulta" (1965).

Por su parte, el Boletín publicó entre las décadas del treinta y del cuarenta unos 65 números con la más variada gama de artículos: reseñas bibliográficas, ensayos bibliotecológicos, textos técnicos e instructivos, historias de bibliotecas, semblanzas biográficas, conclusiones de congresos bibliotecarios, novedades profesionales, traducciones y estadísticas oficiales. Muchos de estos trabajos encarnan ese saber sobre la lectura y la cultura que se consideraba primordial en la agenda del bibliotecario, visto en este marco como una suerte de articulador pedagógico entre la producción editorial y el público popular. Cabe destacar, asimismo, que varios de los autores que colaboraron con la revista Universidad también lo hicieron en el Boletín con idéntica tipología de estudios, tal es el caso de los citados Cónsole, Penna y Buonocore, y de Ernesto Nelson, Germán García, Ernesto Gietz, Federico Finó y Augusto Raúl Cortazar. A esta lista pueden agregarse otros nombres ilustres de la disciplina, entre los que se cuentan José Torre Revello y Guillermo Furlong, dos historiadores clave en la elaboración de la historia de la cultura impresa en Argentina y América Latina. Este tema, que durante las décadas de 1980 y 1990 pareció alejarse de la disciplina -en buena medida porque las sucesivas reformas curriculares en las universidades recortaron el área hasta su mínima expresión-, fue fundacional para las primeras escuelas de bibliotecarios. Manuel Selva - que también aportó con la revista de la Comisión- así lo comprendió y lo dispuso en el primer plan de enseñanza que se hizo efectivo a partir de 1937 en el Museo Social Argentino (Parada, 1997). Su Manual de Bibliotecnia (1939), que debe leerse como un texto pedagógico que recorre el contenido de los cursos, dedica cerca de la mitad de las páginas a dichas problemáticas.

El Boletín y Universidad solo son dos ejemplos de los circuitos periódicos de comunicación bibliotecológica. Como observó Romanos de Tiratel (2008), durante largos años los y las bibliotecarias divulgaron sus artículos en distintas publicaciones generalistas, desde aquellas que patrocinaron las universidades y los órganos estatales como la Comisión, hasta las auspiciadas por asociaciones profesionales, culturales y academias de distintos rubros. La dispersión fue, entonces, una de las características del sistema de comunicación del campo bibliotecario que se mantuvo desde su institución como tal, un fenómeno al que contribuyó otro recurso impreso utilizado sistemáticamente: el folleto. Si bien en muchas oportunidades estos constituían una separata, en otros casos fue una vía de socialización de investigaciones específicas de relativa envergadura y extensión. 
Los tópicos analizados por los bibliotecarios en la serie de intervenciones que recorren este período cambiaron de forma progresiva y, paralelamente, el tipo de producción intelectual ceñida a la aprehensión global del saber y del hacer viró hacia enfoques especializados. Cuando Selva publicó en 1944 el Tratado de Bibliotecnia, una versión notablemente ampliada del Manual del año 39, la obra ya era obsoleta. Quienes fueron sus alumnos y otros tantos colaboradores comenzaron a explorar en profundidad los distintos ámbitos de la Bibliotecología. Y este fenómeno, junto a otras objetivaciones sociales, tecnológicas e institucionales - como las escuelas de bibliotecarios-, fue el que hizo posible una transformación cualitativa de la Bibliotecología en tanto tal, cuyos conocimientos fueron producidos en adelante de forma hegemónica y sistemática en las universidades. A casi un siglo de las primeras cristalizaciones que formaron los cimientos sociales y cognitivos del campo bibliotecario argentino, ese pasaje inauguró un nuevo horizonte para los bibliotecarios.

\section{Especialización del campo bibliotecario (1960-1999)}

Un siglo es mucho tiempo. La observación de los grandes proceso que experimentó el campo bibliotecario y sus lógicas de comunicación del saber parecen indicar que se trató de una curva ascendente, evolutiva: en el comienzo, apenas unas colecciones de libros disgregadas en el territorio y una revista de composición heterodoxa que procuraba darles sentido; más adelante, una compleja, polifónica y multiforme ramificación de instituciones, publicaciones, ámbitos de enseñanza, eventos de intercambio y cientos de instancias de encuentro propiciadas por los concurrentes del campo. Pero esto es una apariencia. El zigzagueante proceso de institucionalización social y cognitiva de la enseñanza universitaria de la Bibliotecología puede brindar una idea del trayecto que se inicia en la mitad del siglo XX con relación a las transformaciones del campo y sus maneras de producir y hacer circular el conocimiento. No es que otros ámbitos bibliotecarios hayan dejado de elaborar discursos sobre las bibliotecas, sean estos normativos, pedagógicos, explicativos o literarios. Pero sin duda, la profesionalización del saber que propició el ingreso de la disciplina en la universidad relegó esos espacios a un segundo plano - como el que hasta entonces había ganado la Comisión Protectora de las Bibliotecas Populares-.

Historias como la formación de los bibliotecarios en la Universidad de Buenos Aires (UBA) o la Universidad Nacional de La Plata (UNLP) muestran, aún al considerar sus diferencias, recorridos que transitan por unas épocas brillantes y otras opacas, alternancias entre períodos de relativo esplendor con cierres temporarios, matriculaciones notables y falta de alumnos, consolidación de un cuerpo estable de docentes con peregrinaciones inciertas, ajustes y reajustes incesantes de planes y programas de estudio. Estos vaivenes no son un patrimonio exclusivo de la disciplina ni de estas instituciones: los sucesivos cambios políticos y presupuestarios en las universidades públicas imposibilitaron objetivar condiciones de relativa estabilidad. Mientras que lo político solo se resolvió con el final del ciclo dictatorial y los procesos de democratización de los años ochenta, lo económico siguió un itinerario marcado por etapas de expansión y contracción del financiamiento.

Aún bajo esas condiciones pendulares el sistema universitario funcionó como polo de atracción para los bibliotecarios, especialmente de aquellos que residían en las ciudades más importantes de Argentina, como Buenos Aires, Córdoba y La Plata. La más ostensible cuestión del prestigio social y la jerarquización de la actividad bibliotecaria que concedía el halo académico resultó una motivación irrecusable para un conjunto de actores siempre acosados por la marginalidad en el universo profesional: escaso reconocimiento, pagas míseras, desamparo sindical, etc. Pero no solo se trató de esto: la cuestión de la comunicación científica se estableció como una preocupación 
prioritaria entre las políticas universitarias y de investigación. En este contexto, los bibliotecarios encontraron un ámbito de radicación laboral que, si bien ya conocían y dominaban en varias de sus dimensiones, les ofrecía nuevos horizontes y promesas para el desarrollo profesional. La trayectoria laboral de Gietz en la organización del sistema documental del Consejo Nacional de Investigaciones Científicas y Técnicas (CONICET) entre las décadas del cincuenta y el ochenta conforma una prueba irrefutable del movimiento que experimentó el campo (Solari, 2013). Un movimiento que también tuvo sus resonancias en la preponderancia de los temas de indagación bibliotecaria y en las formas de producción y circulación del saber. Estos efectos, inicialmente, deben localizarse en la solidaridad social y funcional que se extendió entre las bibliotecas especializadas instaladas en las universidades y los ámbitos de preparación de los bibliotecarios que estas mismas universidades dispusieron. Todavía más: en muchos casos se trató del mismo grupo de personas que transitaron por esos dos ámbitos.

La imbricación histórica precedente sugiere algunos dilemas. En el plano teórico, resulta complejo determinar hasta qué punto fue la demanda social la que delineó un perfil formativo o, a la inversa, si fue la oferta de bibliotecarios la que activó un sector de la demanda que permanecía dormido desde las citadas intentonas bibliográficas trasnacionales de principios de siglo. En términos historiográficos, los trabajos de Amelia Aguado (2009) para el caso de la UNLP y de Stella Maris Fernández (1996) para la UBA, casi los únicos que se ocupan del asunto, corroboran el desarrollo de ese proceso. Durante las últimas tres décadas del siglo XX, en especial luego de la reapertura democrática que conocieron las universidades argentinas a partir de 1983 , se produce un acercamiento inédito entre los contenidos impartidos desde las aulas y los problemas vinculados a la profesionalización de las bibliotecas universitarias. De forma progresiva, la tecnología expresada en el pasaje de los catálogos tradicionales a los automatizados, junto con el análisis del sistema de comunicación científica, adquirieron preponderancia en el trayecto formativo de los futuros bibliotecarios. De forma paralela fueron relegados otros tópicos, incluso algunos que habían sido fundacionales poco tiempo antes. Un ejemplo notable es el contraste verificable en los temas relativos a la elaboración de un discurso público sobre la lectura: mientras que el período previo a los sesenta y setenta era moneda corriente entre los bibliotecarios, en adelante estas tematizaciones perdieron el poder instituyente del que estaban dotadas.

La suma de esos procesos sociales e institucionales condicionaron las formas de producción del saber bibliotecario y las prioridades investigativas del campo, ya se trate de la emergencia y el tratamiento de problemáticas propiamente locales, como de aquellas que se fundaron bajo la inspiración de marcos interpretativos elaborados en el exterior, una consecuencia esperable de la aceleración de los intercambios internacionales que la disciplina experimentó luego de la segunda guerra mundial a partir de iniciativas de formación profesional como las que impulsó la UNESCO para toda América Latina. Sin embargo, estos elementos no determinan por sí mismos la constitución y la jerarquización de los temas vigentes de indagación ni sus formas de circulación. La querella sobre cómo se ordena y desenvuelve la investigación científica es de larga data en la filosofía y la sociología de la ciencia. Bourdieu observó, por ejemplo, que no basta con oponer de modo abstracto los elementos intrínsecos o epistemológicos de la creatividad a los que pudieran ser reconocidos como extrínsecos o sociales. No bastan porque la ciencia no es sencilla y únicamente la búsqueda de la verdad ni la respuesta a circunstancias coyunturales. En la perspectiva del autor, los problemas y las elecciones son el producto de las apuestas sucesivas de los actores por el reconocimiento que solo le pueden brindar sus pares (Bourdieu, 1999). No es que dichos elementos -epistémicos y sociales- no estén comprendidos en esta red de relaciones que es el campo científico o, para el caso, el campo bibliotecario. No 
están considerados como fenómenos aislados o separados de quienes juegan el juego. Toda vez que los productores de los saberes legítimos ejecutan su arte u oficio, ponen en acción una serie recursos objetivos, medibles en disponibilidad de infraestructura, bibliografía, etc., y otros incorporados, perceptibles como formación adquirida, trayectorias, etc. Asimismo, esas voluntades y los efectos de su hacer están inscriptos en contextos institucionales que ordenan sus flujos de circulación.

El conjunto de disposiciones que genera la serie de condicionamientos enunciados de forma precedente explica por qué los actores que participaron de esta última transformación del campo bibliotecario en la Argentina volcaron sus producciones hacia las revistas con pretensiones académicas. Estos dispositivos textuales, junto con las instancias de enseñanza ya instituidas, conforman los instrumentos principales de la consagración y la vigencia (o conservación) de los conocimientos y de los concurrentes del campo (del bibliotecario o de cualquier otro). Las primeras publicaciones bibliotecológicas que aspiraron a ocupar ese lugar en Argentina surgieron de forma paralela a la radicación y estabilización de las titulaciones en las universidades en el final de la década de 1970 y, con algo más de energía, en los ochenta y noventa (Romanos de Tiratel, 2008). Estas revistas no se caracterizaron, sin embargo, por presentarse como proyectos de larga duración, por seguir de forma rigurosa las reglas ancestrales de la revisión por pares o, siquiera, por respetar una frecuencia regular. Paradójicamente, quienes más conocían los sistemas y los flujos de la información científica no pudieron cristalizar una publicación periódica en el marco de las reglas del juego que por entonces marcaban el inicio de una nueva era para la edición, en adelante signada por la concentración de los consorcios, la compra y venta de títulos y los rankings de popularidad gestados por las empresas privadas. Los presupuestos acotados y la conducción artesanal de la edición en un mundo altamente profesionalizado conspiraron contra la objetivación de las pretensiones de representación cognitiva que distintos grupos de bibliotecarios sostuvieron. No menos fundamental resultó el volumen y la calidad de la producción intelectual y, desde ya, el poder de atracción que esas revistas generaron en el plano internacional, pero también hacia el interior de los colectivos locales. Recién en el final de la década de 1990 aparece Información, Cultura y Sociedad, la primera publicación periódica de la Argentina cuyas características, en conjunto, delimitaron la aspiración genuina a participar en el nuevo ámbito de la comunicación científica internacional.

\section{Conclusiones}

Al recapitular los pasos seguidos en el presente artículo, es posible extraer las siguientes constataciones:

1. En relación con los antecedentes disponibles en la materia, el trabajo contribuye a constituir un espacio de investigación al asociar los procesos de formación del campo bibliotecario en la Argentina y con las maneras de producción y circulación del conocimiento que le fueron propias en cada momento. En términos teóricos, el artículo propone una apropiación de las nociones de campo e institución como marcos conceptuales y metodológicos para ordenar, seleccionar e interpretar un repertorio amplio y disperso de documentos y bibliografía que, en conjunto, forma parte de la base elemental del objeto de conocimiento presentado.

2. La noción de institución expresa un modo diacrónico de asir la trayectoria de las bibliotecas y de la Bibliotecología en la Argentina que aspira a evidenciar, por sobre todas las cosas, la fundación de una experiencia social gestada entre 1870 y 1910 , cuyas resonancias a lo largo de los años hicieron posible explicar y dar sentido a todos los procesos y todos los discursos que antes y después se asociaron con la idea 
de biblioteca (como establecimiento, como objeto de estudio, etc.). Si este modo de aprehensión remite al reconocimiento de un fenómeno de potencia durable en lo social, el concepto campo introduce una perspectiva sincrónica, es decir, un modo de asir y comprender los diferentes estados del campo. A través del análisis de los materiales propuesto como el corpus inicial de la investigación se detectaron tres momentos o estados del campo: el de emergencia, el de prolongación y expansión, y el de especialización.

3. La aproximación panorámica presentada procura disponer un horizonte, construir un objeto de estudio a partir de unos conceptos y unas constataciones factuales iniciales. Entre estas, se destaca: en primer lugar, la presencia de un enorme archivo del saber bibliotecario que testimonia las voluntades de diferentes personas e instituciones que invirtieron tiempo y recursos en hacer y pensar la biblioteca y la Bibliotecología; en segundo orden, la extensión de una serie de preocupaciones principales que reunieron a esas personas y a esas instituciones bajo un mismo ámbito de debate; finalmente, los virajes fundamentales en la estructura misma del campo, conforme pasaron los años y se resolvieron o abandonaron algunos problemas y aparecieron otros nuevos.

4. El artículo brinda un punto de partida que ofrece, en conjunto, una perspectiva interpretativa de un fenómeno de larga duración que podrá ser retomada, profundizada, discutida y hasta rebatida por nuevas investigaciones que aporten pruebas e hipótesis más convincentes de las que fueron presentadas. En definitiva, se trata al fin de cuentas de dar un paso más en el todavía incipiente y rico campo que enlaza la historia de la biblioteca con la historia del saber que fue su causa y su efecto. 


\section{Q Referencias bibliográficas}

" Aguado, Amelia. 2009. Sesenta años en procura de un buen bibliotecario. 8 p. Conferencia pronunciada en la Jornada por los 60 años de la carrera de Bibliotecología en la Universidad Nacional de La Plata, realizadas en La Plata, el 4 de septiembre de 2009.

» Baczko, Bronislaw. 1999. Los imaginarios sociales: memorias y esperanzas colectivas. Buenos Aires: Nueva Visión.

»Bourdieu, Pierre. 1999. El campo científico. En Intelectuales, política y poder. Buenos Aires: Eudeba. p. 75-110.

"Bourdieu, Pierre. 2002. Algunas propiedades de los campos. En Campo de poder, campo intelectual. Itinerario de un concepto. Buenos Aires: Montressor.

»Buchbinder, Pablo. 2018. Vicente Quesada, la Biblioteca Pública de Buenos Aires y la Construcción de un espacio para la práctica y la sociabilidad de los letrados. En Aguirre, C. y Salvatore, R. D., ed. Bibliotecas y cultura letrada en América Latina: siglos XIX y XX. Lima: Pontificia Universidad Católica, Fondo Editorial. p. 149-166.

" Capurro, Rafael. 2015. ¿Qué es una revista científica? En Informatio. Vol. 20, no. 1, 3-24 <http://informatio.eubca.edu.uy/ojs/index.php/Infor/article/ view/169/250> [Consulta: 11 diciembre 2018].

»Fernández, Stella Maris. 1996. La formación profesional del bibliotecario en la Facultad de Filosofía y Letras: 74 años de existencia. En La investigación, las bibliotecas y el libro en cien años de vida de la Facultad de Filosofía y Letras de la Universidad de Buenos Aires. Buenos Aires: UBA. p. 359-392.

"González, Horacio. 2010. Historia de la Biblioteca Nacional. Estado de una polémica. Buenos Aires: Biblioteca Nacional.

"Laudano, Claudia; Javier Planas; Pamela Pelliti y Cecilia Corda. 2011. La cuestión tecnológica en los planes de estudio de la Carrera de Bibliotecología de la Universidad Nacional de La Plata. Aproximaciones críticas desde los documentos y la mirada de los actores. En Información, Cultura y Sociedad. No. 24, 69-86. <http://revistascientificas.filo.uba.ar/index.php/ICS/article/ view/735> [Consulta: 11 diciembre 2018].

" Menéndez Navarro, Alfredo; Guillermo Olagüe de Ros y Mikel Astrain Gallart. 2002. Ciencia, positivismo e identidad nacional en el cono sur: la participación argentina en los proyectos documentales contemporáneos (1895-1928)". En Hispania. Vol. 62, no. 210, 221-258. Doi: https://doi.org/10.3989/hispania.2002. v62.i210.271

" Merleau-Ponty, Maurice. 2012. La institución. La pasividad. Notas de cursos en el Collége de France (1954-1955). La institución en la historia personal y pública. Buenos Aires: Anthropos.

"Parada, Alejandro E. 1997. Manuel Selva y los estudios bibliográficos y bibliotecológicos en la Argentina. Tributo a un maestro olvidado. En Boletín de la sociedad de estudios bibliográficos argentinos. No. 3, 21-58.

"Parada, Alejandro E. 2009. Los orígenes de la Biblioteca Pública de Buenos Aires: antecedentes, prácticas, gestión y pensamiento bibliotecario durante la revolución 
de mayo. Buenos Aires: Instituto de Investigaciones Bibliotecológicas, Facultad de Filosofía y Letras, Universidad de Buenos Aires.

»Parada, Alejandro E. 2014. El dédalo y su ovillo. Ensayos sobre la palpitante cultura impresa en la Argentina. Buenos Aires: Instituto de Investigaciones Bibliotecológicas, Facultad de Filosofía y Letras, Universidad de Buenos Aires.

»Planas, Javier. 2017. Libros, lectores y sociabilidades de lectura. Una historia de los orígenes de las bibliotecas populares en la Argentina. Buenos Aires: Ampersand.

»Planas, Javier. 2018. Saberes sobre bibliotecas y saberes sobre la lectura. Elaboraciones discursivas durante las primeras décadas del siglo XX. 12p. Trabajo presentado en el III Coloquio Argentino de Estudios sobre el Libro y la Edición, realizado del 7 al 9 de noviembre de 2016.

»Romanos de Tiratel, Susana; Graciela M. Giunti, Nora C. López, Alejandro E. Parada y María Alejandra Plaza. 2008. Revistas argentinas de humanidades y ciencias sociales. Visibilidad en bases de datos internacionales. Buenos Aires: Instituto de Investigaciones Bibliotecológicas, Facultad de Filosofía y Letras, Universidad de Buenos Aires.

» Sik, M. Eugenia. 2016. Ángel M. Giménez, bibliotecario. Apunte para una historia de las bibliotecas obreras en Argentina. 20 p. Trabajo presentado en el II Coloquio Argentino de Estudios sobre el Libro y la Edición, realizado en Córdoba del 21 al 23 de septiembre de 2016.

» Sik, M. Eugenia. 2018. La creación de bibliotecas durante el apogeo del anarquismo argentino, 1898-1905. En Historia y Espacio. Vol. 14, no. 5. Doi: 10.25100/ hye.v14is1.6984.

»Solari, Tomás. 2013. Un sistema de información para la ciencia argentina: biografía de Ricardo A. Gietz (1932-1998). En Información, Cultura y Sociedad. No. 29, 77-116. <http://revistascientificas.filo.uba.ar/index.php/ICS/article/ view/676> [Consulta: 11 diciembre 2018].

» Tripaldi, Nicolás. 1997. Origen e inserción de las bibliotecas obreras en el entorno bibliotecario argentino: fines del siglo XIX y primer tercio del siglo XX. En Libraria: Correo de las Bibliotecas. Vol. 1, no. 1, 22-37.

\section{Fuentes}

"Birabén, Federico. 1904. La futura biblioteca universitaria. Buenos Aires: Imprenta Diot, de Félix Lajouane. (Separata de la Revista Universidad de Buenos Aires).

»Boletín de las Bibliotecas Populares. 1872-1875. Buenos Aires: Comisión Protectora de las Bibliotecas Populares, números 1-6.

»Boletín de la Comisión Protectora de las Bibliotecas Populares. 1933-1947. Buenos Aires: Comisión Protectora de Bibliotecas Populares, números 1-65.

»Cortazar, Augusto Raúl. 1956. Visión sintética de un curso de introducción a la bibliotecología. Santa Fe: Universidad Nacional del Litoral.

»Finó, Federico y Luis Hourcade. 1952. Evolución de la bibliotecología argentina (1757-1952). Santa Fe: Universidad Nacional del Litoral.

»Fors, Luis Ricardo. 1900. “Biblionomía”. En Boletín de la Biblioteca Pública de la Provincia de Buenos Aires, números 1-21.

»Groussac, Paul. 1893. Catálogo metódico de la biblioteca. Buenos Aires: Biblioteca Nacional. 
"Lucero, Amador. 1910. Nuestras bibliotecas desde 1810. Buenos Aires: Coni.

»Matijevic, Nicolás. 1969. Bibliografía bibliotecológica argentina (hasta el año 1967). Bahía Blanca: Universidad Nacional del Sur.

» Montes de Oca, Marta. 1965. Índice General de Universidad. Santa Fe: Universidad Nacional del Litoral.

"Penna, Carlos Víctor. 1960. La bibliotecología Latinoamericana. Algunas consideraciones sobre su pasado, esbozo de un plan para acelerar su desarrollo. Tucumán: Biblioteca central. Universidad Nacional de Tucumán.

"Quesada, Vicente. 1877. Las bibliotecas europeas y algunas de América Latina: con un Apéndice sobre el Archivo General de Indias en Sevilla, la Dirección de Hidrografía y la Biblioteca de la Real Académica de la Historia en Madrid. Buenos Aires: Imprenta y Librerías de Mayo.

»Quesada, Vicente. 1879. La Biblioteca Pública de Buenos Aires: proyecto de reorganización. Buenos Aires: Imprenta de Biedma.

» Sarmiento, Domingo Faustino. 1877a. Bibliotecas populares. En La Educación Común, t. 2, no. 6, 175-185.

»Sarmiento, Domingo Faustino. 1877b. Bibliotecas Europeas y algunas en América Latina, por Vicente Quesada, Director de la Biblioteca de Buenos Aires. En La educación Común, t. 2, no. 7, 207-219.

"Selva, Manuel. 1939. Manual de bibliotecnia. Buenos Aires: Julio Suarez.

"Selva, Manuel. 1944. Tratado de bibliotecnia. Buenos Aires: Julio Suarez.

» Universidad. Publicación de la Universidad Nacional del Litoral. 1935-1965. Santa Fe: La universidad, números 1-50. 
